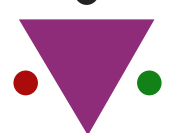

IJCRR

Section: Healthcare

Sci. Journal Impact

Factor: $6.1(2018)$

ICV: 90.90 (2018)

(c) (i) (3)

Copyright@IJCRR

\title{
Awareness on Dental Treatment During COVID-19 Among South Indian Population
}

\section{Soorya Ganesh ${ }^{1}$, Vishnu Priya V ${ }^{2}$, Gayathri $\mathbf{R}^{3}$, Kavitha $\mathbf{S}^{4}$}

'Saveetha Dental College and Hospitals, Saveetha Institute of Medical and Technical Sciences (SIMATS), Saveetha University, Chennai-60oo77; India; 'Department of Biochemistry, Saveetha Dental College and Hospitals, Saveetha Institute of Medical and Technical Sciences (SIMATS), Saveetha University, Chennai-600077, India; ${ }^{3}$ Department of Biochemistry, Saveetha Dental College and Hospitals, Saveetha Institute of Medical and Technical Sciences (SIMATS), Saveetha University, Chennai-60oo77, India; ${ }^{2}$ Department of Biochemistry, Saveetha Dental College and Hospitals, Saveetha Institute of Medical and Technical Sciences (SIMATS), Saveetha University, Chennai-60oo77., India.

\section{ABSTRACT}

Introduction: In the current COVID-19 pandemic, frontline health care workers and patients undergoing dental procedures are at the high risk of cross-infection. Most of the dental procedures require contact with the saliva, blood, and respiratory tract secretions in the oral cavity of the patient. Many patients may be carriers of the virus. It may be suggested that all patients visiting a dental office must be treated with due precautions and utmost care to prevent the cross-infection. The aim of this study was to create awareness on dental treatment during COVID-19 among the South Indian population.

Materials and Methods: A self-structured questionnaire was administered to the participants to collect the data through online Google forms link. The participants were well informed about the study in detail. The data were collected and statistically analyzed.

Results and Conclusion: People need to be educated about their personal hygiene which will prevent the disease spread. Awareness seminars may be conducted to educate the community about dental treatment in this pandemic period.

Conclusion: Closing dental practices during the pandemic will increase the suffering of individuals in need of urgent dental care. This calls for the designing of standard guidelines for dental care during the worldwide spread of the pandemic. Awareness may be created on the use of masks, hand sanitizers, and social distancing for patients to prevent the disease spread.

Key Words: COVID-19, Aerosol, Online survey, Dentist, Survey planet, Hygiene.

\section{INTRODUCTION}

Coronavirus disease 2019 is an infectious disease caused by severe acute respiratory syndrome coronavirus ${ }^{1}$. The disease was first identified in December 2019 in Wuhan, the capital of China's Hubei province, and has since spread globally which resulting in the ongoing 2019-2020 coronavirus pandemic $^{2}$. Most recently, the Middle East respiratory syndrome coronavirus (MERS-COV) was first identified in Saudi Arabia in $2012^{3}$. In a timeline, reaches the present day which is an epidemic of cases with unexplained low respiratory infection detected in Wuhan, the largest metropolitan area in China's Hubei province which was first reported to the WHO country office in China on December 31, $2019^{4}$.

Researchers around the world are working to develop potential treatments or vaccines against the respiratory diseases that have killed nearly 47,000 people infected almost a million in just a few months ${ }^{5}$. Coronavirus is popular as it spreads to many countries around the world ${ }^{6}$. This research is needed to analyze the important statistics on COVID 19 virus and make awareness among people about the consequences of COVID 19 virus $^{7}$. People may be sick with the virus for 1 to 14 days before developing symptoms ${ }^{8}$. The most people recover from the disease without needing any special treatment ${ }^{9,10}$.

The most common symptoms of coronavirus disease are fever, tiredness, and dry cough. Most people recover from the disease without needing any special treatment. Most advanced research on nanomaterials ${ }^{11-16}$, natural products in health and disease ${ }^{17-21}$, cirrhosis $^{22}$, enzyme studies ${ }^{23}$, juvenile obesity ${ }^{24,25}$ motivated my interest in research and this study was much very suitable in this pandemic lockdown. The aim of this study was to create awareness on dental treatment during COVID-19 among the South Indian population.

\section{Corresponding Author:}

V. Vishnu Priya, Department of Biochemistry, Saveetha Dental College and Hospitals, Saveetha Institute of Medical and technical Sciences (SIMATS), Saveetha University, Chennai-600077, India; Email: vishnupriya@saveetha.co

ISSN: 2231-2196 (Print)

Received: 24.07 .2020
ISSN: $0975-5241$ (Online)

Revised: 18.08 .2020
Accepted: 22.09 .2020
Published: 20.10 .2020 


\section{MATERIALS AND METHODS}

The study consists of a well-structured questionnaire comprising 15 questions covering social-demographic information, knowledge, attitude, the perception was framed, and administered to the participants through Google forms.

The advantages of this survey were economical, easy to create, wide reach among the population, gathers large data, and quick interpretation. It is approved by the scientific review board at Saveetha Dental College, Chennai. The sample size of the survey is 100 participants of 25-50 years of age. The sampling method of this survey was a non-probability convenient method.

The Google link for the study is as follows: https://forms.gle/ qGioCx57bj4kK36e6

\section{Statistical Analysis}

The methods of representation of each output variable are the pie chart. The data were collected and statistically analyzed with SPSS software.

\section{RESULTS AND DISCUSSION}

The results are based on the survey reports, 15 questions were answered and all questions were answered by the 100 respondents. No questions were skipped in this survey.

$54.46 \%$ of the participants were men and $45.54 \%$ were women (Fig. 1). $87.13 \%$ answered yes and $12.87 \%$ answered no for the awareness on the spread of coronavirus (Fig. 2). $89.11 \%$ of the participants were aware of social distancing and $10.89 \%$ were unaware (Fig. 3).

$87.13 \%$ were aware of the risk of spread involved during dental treatment (Fig. 4). $44.55 \%$ for contact, $22.77 \%$ for water during the procedure, and $32.67 \%$ for the saliva were responses for the mode of spread of COVID-19 (Fig. 5).

$34.65 \%$ for fever, $14.85 \%$ for cough, $6.93 \%$ for throat pain, and $43.56 \%$ for all of the above are aware that dental procedures cannot be perfumed during that period. (Fig. 6). $63.07 \%$ answered possible and $6.93 \%$ answered not possible for awareness of the transmission of infection during dental treatment (Fig. 7). $80.2 \%$ of the participants were aware of aerosol contamination and $19.80 \%$ were unaware (fig 8). $88.12 \%$ of the participants reported that they require information during COVID-19 for proceeding dental procedures (Fig. 9).

$48.51 \%$ for Yes, $18.81 \%$ answered No, and $32.67 \%$ answered maybe are aware of carriers in COVID 19 (Fig. 10). 83.17\% answered Yes and $16.83 \%$ answered No for how to spread infection (Fig. 11). 56.44\% answered Yes, $21.78 \%$ to understand the present scenario in dental treatment, and $21.78 \%$ for overall knowledge of COVID-19 (Fig. 12).
Association between gender and awareness on social distancing was seen in which $47 \%$ of males and $43 \%$ of females were aware of social distancing (Fig. 13). Association between gender and awareness on COVID-19 was observed in which $47 \%$ of males were aware of COVID 19 (Fig. 14). Association between gender and awareness on the reason for the spread of COVID-19 was shown in which $46 \%$ of males and $42 \%$ of females are aware of the reason for the widespread of COVID-19 (Fig 15).

Association between gender and awareness on the risk of spread involved during dental treatment was observed in which $55 \%$ of males and $46 \%$ of females were aware of the risk of spread involved during dental procedures (Fig. 16). Association between the gender and awareness on the mode of transmission was observed in which $20 \%$ of males and $25 \%$ of the female participants reported that direct contact is the mode of transmission (Fig. 17). The association between gender and awareness of aerosol contamination during dental procedures are presented where $39 \%$ of the female and $42 \%$ of the male are aware of aerosol contamination (Fig. 18).

This survey states that the many people aware of COVID-19 but some of the population in class-3 and class-4 workers do not know the effects of COVID-19. So the literate people should educate them about the risk factors, precautions to be taken in this pandemic.

The previous studies have only described the effect, prevention, and symptoms of COVID-19. But this survey describes the additional information on COVID-19 disease during dental treatment during COVID-19 disease. It also discusses the challenges that we face currently and offers some simple strategies to bridge the gaps in dental education to overcome this emergency.

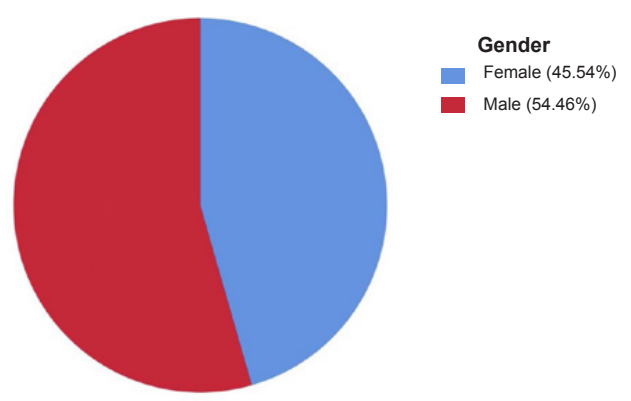

Figure 1: Pie chart showing the percentage distribution of gender responses. $55 \%$ were male (red) and $45 \%$ were female (blue). 


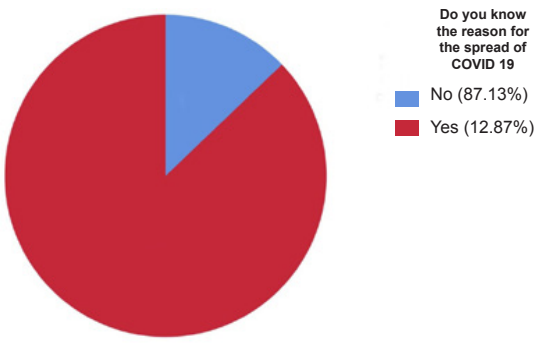

Figure 2: Pie chart showing the percentage distribution of responses for the causes of COVID-19 spread. $19.87 \%$ answered Yes (red) and 13\% answered No (blue).

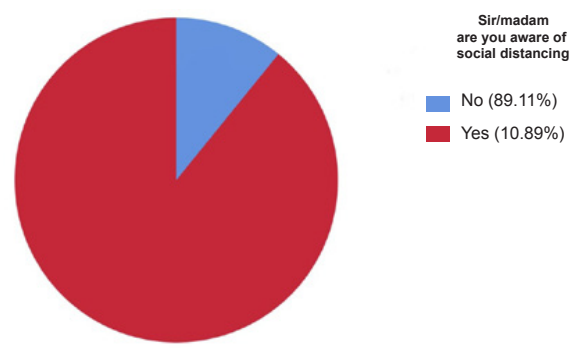

Figure 3: Pie chart showing the percentage distribution of responses about the awareness of social distancing. $89 \%$ are aware of social distancing (red) and $11 \%$ were not aware of social distancing (blue).

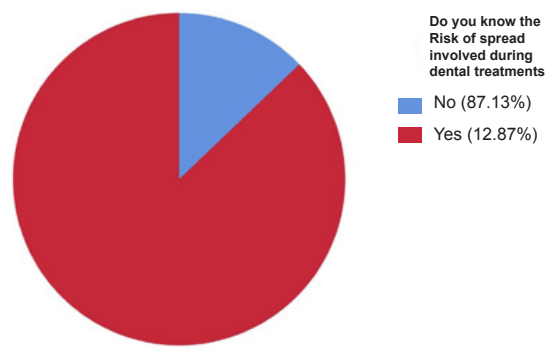

Figure 4: Pie chart showing the percentage distribution of responses of awareness on risk factors for COVID-19 spread during dental treatment. $87 \%$ answered Yes (red) and $13 \%$ answered No (blue).

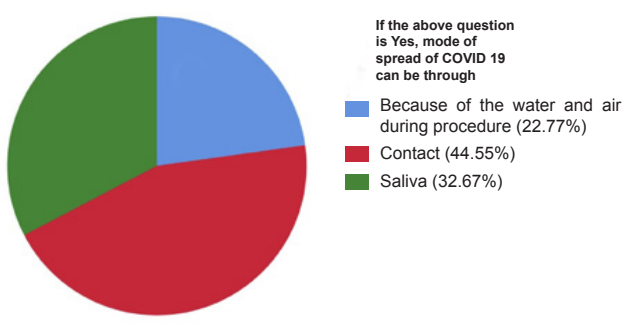

Figure 5: Pie chart showing the percentage distribution of responses of awareness about the mode of disease spread. $19.44 \%$ answered contact (orange), 23\% answered because of the water during the procedure (red) and $33 \%$ answered saliva (green).

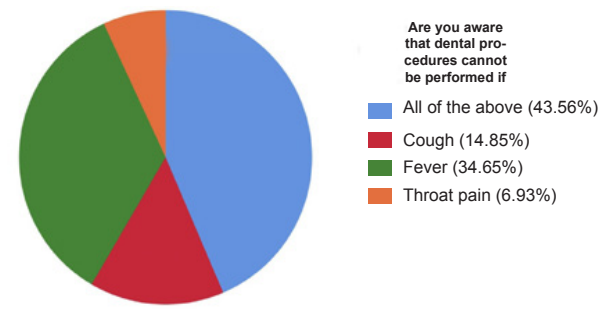

Figure 6: Pie chart showing the percentage distribution of responses about awareness of dental procedures. 35\% answered fever (green), 15\% answered cough (red), $7 \%$ answered throat pain (orange), and $44 \%$ answered all of the above (blue).

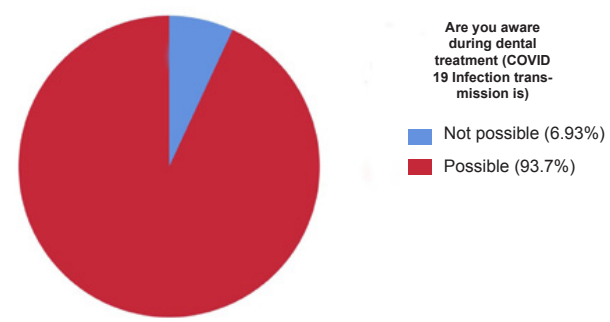

Figure 7: Pie chart showing the percentage distribution of responses about awareness of infection during dental treatment in pandemic condition. 93\% answered possible (red) and 7\% answered not possible (blue).

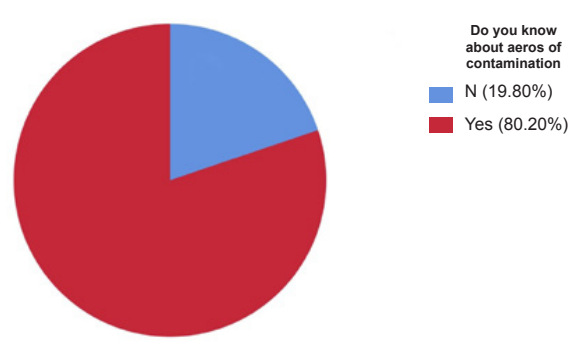

Figure 8: Pie chart showing the percentage distribution of responses about awareness on aerosol contamination. $80 \%$ answered Yes (red) and 20\% answered No (blue).

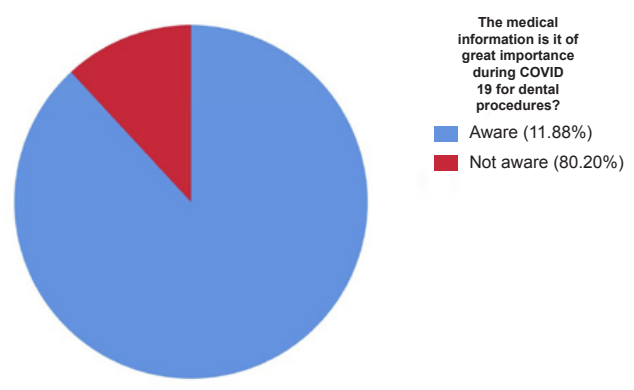

Figure 9: Pie chart showing the percentage distribution of responses of awareness on the importance of information during COVID-19 for dental procedures. $88.12 \%$ were aware (blue), $11.88 \%$ were not aware (red). 


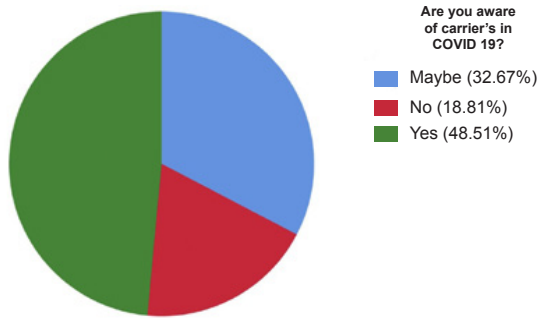

Figure 10: Pie chart showing the percentage distribution of responses about the awareness of carriers in COVID-19. $49 \%$ answered Yes (green), 19\% answered No (red) and 33\% answered Maybe (blue).

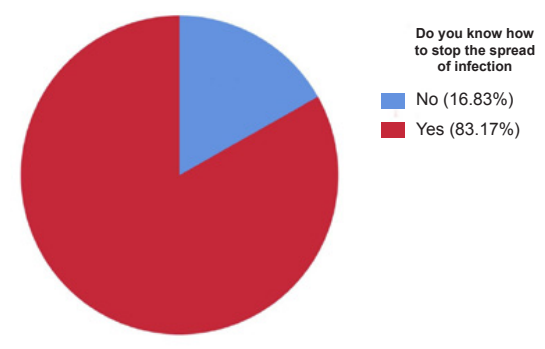

Figure 11: Pie chart showing the percentage distribution of responses about awareness on steps taken to prevent the spread of infection. 83\% answered, "Yes" (red) and 17\% answered, "No"(blue).
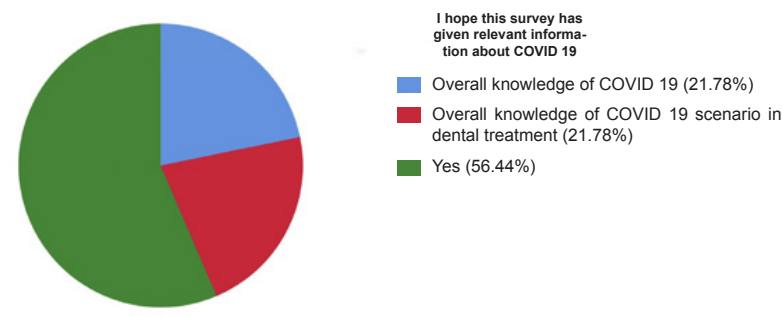

Figure 12: Pie chart showing the percentage distribution of responses about awareness on this survey giving relevant information about COVID-19. 22\% answered overall knowledge of COVID-19 (blue), 22\% answered to understand the present scenario in dental treatment (red) and 57\% answered Yes (green).

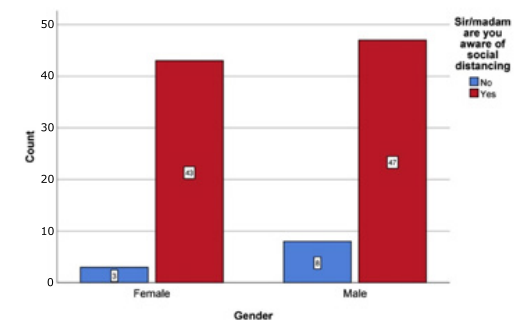

Figure 13: Bar graph represents the association between gen$\operatorname{der}(\mathrm{X}$-axis) and responses of awareness on social distancing ( $\mathrm{Y}$ axis). $43 \%$ of the female participants and $47 \%$ of the male participants are aware of social distancing. Blue color denotes No and red denotes Yes. A significant difference is not seen though male participants are more aware than females. Chi-square value $=$ 1.662, $P$-value $=0.197$ ( $P>0.05$, statistically not significant).

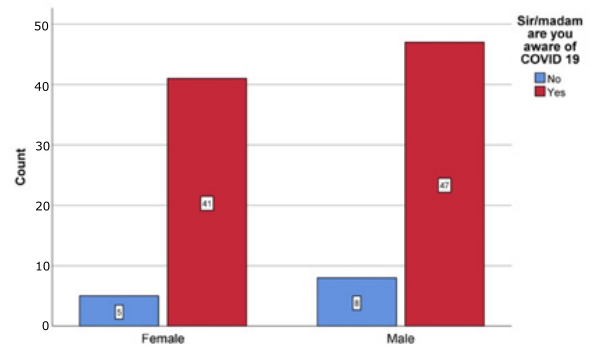

Figure 14: Bar graph represents the association between gender (X-axis) and responses of awareness on COVID-19 (Y-axis). $47 \%$ of males and $41 \%$ of females are aware of COVID-19. Red color denotes Yes and blue color denotes No. A significant difference is not seen though male participants are more aware than females. Chi-square value $=0.302, \mathrm{P}$-value $=0.583(P>0.05$, statistically not significant $)$.

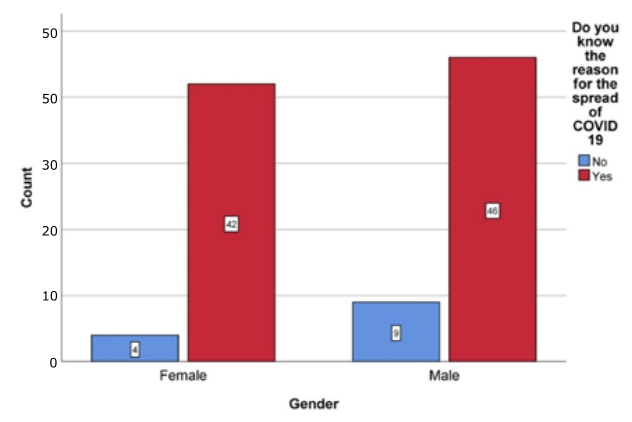

Figure 15: Bar graph represents the association between gen$\operatorname{der}(\mathrm{X}$-axis) and responses of awareness on the reason for the spread of COVID-19 (Y-axis). $46 \%$ of males and $42 \%$ of females are aware of the reason for the widespread COVID-19. Red color denotes yes and blue color denotes No. Chi-square value $=1.313, \mathrm{P}$-value $=0.252(\mathrm{P}>0.05$, statistically not significant).

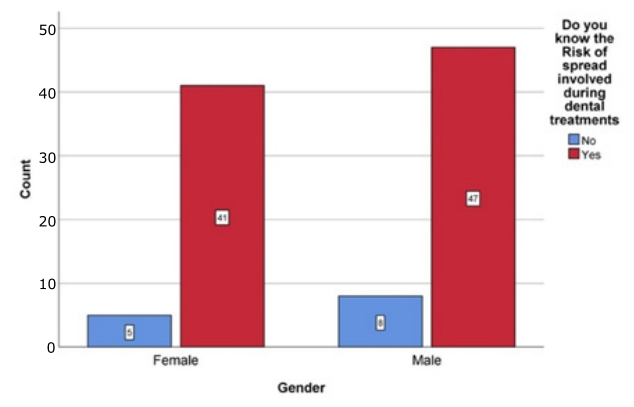

Figure 16: Bar graph represents the association between gender (X-axis) and responses of awareness on risk of spread involved during dental treatment (Y-axis). $55 \%$ of males and $46 \%$ of females are aware of the risk of spread involved during dental procedures. Red color denotes yes and blue color denotes no. Chi-square value $=0.302, \mathrm{P}$-value $=0.583(\mathrm{P}>0.05$, statistically not significant). 


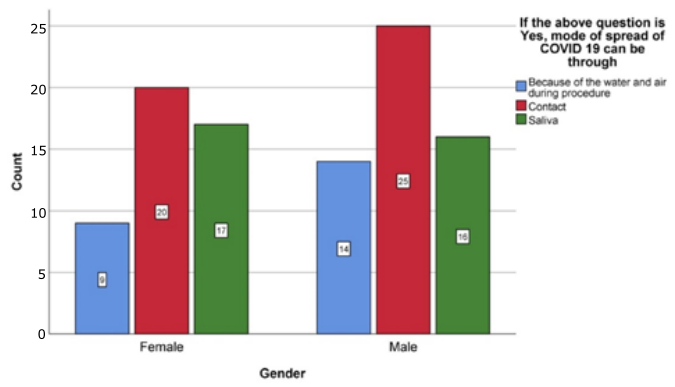

Figure 17: Bar graph showing the association between the gender (X-axis) and responses of awareness on the mode of transmission (Y-axis). $20 \%$ of the male and $25 \%$ of the female participants reported that direct contact is the mode of transmission. Blue color denotes transmission water and air procedures, red denotes direct contact and green denotes transmission due to saliva. Chi-square value $=0.878, \mathrm{P}$-value $=0.645$ ( $P>0.05$, statistically not significant).

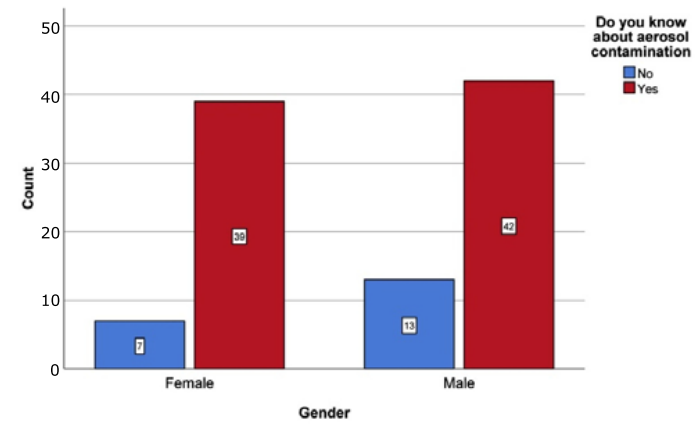

Figure 18: Bar graph showing the association between the gender (X-axis) and responses of awareness on aerosol contamination during dental procedures (Y-axis). 39\% of the females and $42 \%$ of the males are aware of aerosol contamination. Blue color denotes no and red denotes yes. Chi-square value=1.118, $P$-value $=0.290(P>0.05$, statistically not significant $)$

\section{CONCLUSION}

Closing dental practices during the pandemic will increase the suffering of the individuals in need of urgent dental care. This calls for the designing of standard guidelines for dental care during the worldwide spread of the pandemic. Awareness may be created on the use of masks, hand sanitizers, and social distancing for patients to prevent the disease spread.

\section{ACKNOWLEDGEMENT}

We thank Saveetha dental college for providing us the support to conduct the study.

\section{Conflict of Interest}

Nil

\section{Funding Information}

None

\section{REFERENCES}

1. Johnson J, Lakshmanan G, Biruntha M, Vidhyavathi RM, Kalimuthu K, Sekar D. Computational identification of MiRNA-7110 from pulmonary arterial hypertension (PAH) ESTs: An new microRNA that links diabetes and PAH [Internet]. Vol. 43, Hypertension Research. 2020. p. 360-2. Available from: http:// dx.doi.org/10.1038/s41440-019-0369-5

2. Sekar D, Lakshmanan G, Mani P, Biruntha M. Methylationdependent circulating microRNA 510 in preeclampsia patients [Internet]. Vol. 42, Hypertension Research. 2019. p. 1647-8. Available from: http://dx.doi.org/10.1038/s41440-019-0269-8

3. Rothan HA, Byrareddy SN. The epidemiology and pathogenesis of coronavirus disease (COVID-19) outbreak [Internet]. Vol. 109, Journal of Autoimmunity. 2020. p. 102433. Available from: http://dx.doi.org/10.1016/j.jaut.2020.102433

4. Turner AJ, Hiscox JA, Hooper NM. ACE2: from vasopeptidase to SARS virus receptor [Internet]. Vol. 25, Trends in Pharmacological Sciences. 2004. p. 291-4. Available from: http://dx.doi. org/10.1016/j.tips.2004.04.001

5. Wittkowski KM. The first three months of the COVID-19 epidemic: Epidemiological evidence for two separate strains of SARS-CoV-2 viruses spreading and implications for prevention strategies [Internet]. Available from: http://dx.doi. org/10.1101/2020.03.28.20036715

6. Maier HJ, Bickerton E, Britton P. Coronaviruses: Methods and Protocols. Humana Press; 2015. 285 p.

7. Li Q, Guan X, Wu P, Wang X, Zhou L, Tong Y, et al. Early Transmission Dynamics in Wuhan, China, of Novel Coronavirus-Infected Pneumonia. N Engl J Med. 2020 Mar 26;382(13):1199207.

8. Sun P, Lu X, Xu C, Sun W, Pan B. Understanding of COVID-19 based on current evidence. J Med Virol [Internet]. 2020 Feb 25; Available from: http://dx.doi.org/10.1002/jmv.25722

9. Sun P, Lu X, Xu C, Sun W, Pan B. Understanding of COVID-19 based on current evidence. J Med Virol [Internet]. 2020 Feb 25; Available from: http://dx.doi.org/10.1002/jmv.25722

10. Bassetti M, Vena A, Giacobbe DR. The novel Chinese coronavirus (2019-nCoV) infections: Challenges for fighting the storm [Internet]. Vol. 50, European Journal of Clinical Investigation. 2020. Available from: http://dx.doi.org/10.1111/eci.13209

11. Wu F, Zhu J, Li G, Wang J, Veeraraghavan VP, Mohan SK, et al. Biologically synthesized green gold nanoparticles from Siberian ginseng induce growth-inhibitory effect on melanoma cells (B16) [Internet]. Vol. 47, Artificial Cells, Nanomedicine, and Biotechnology. 2019. p. 3297-305. Available from: http:// dx.doi.org/10.1080/21691401.2019.1647224

12. Ke Y, Al Aboody MS, Alturaiki W, Alsagaby SA, Alfaiz FA, Veeraraghavan VP, et al. Photosynthesized gold nanoparticles from Catharanthus roseus induces caspase-mediated apoptosis in cervical cancer cells (HeLa) [Internet]. Vol. 47, Artificial Cells, Nanomedicine, and Biotechnology. 2019. p. 1938-46. Available from: http://dx.doi.org/10.1080/21691401.2019.1614017

13. Li Z, Veeraraghavan VP, Mohan SK, Bolla SR, Lakshmanan H, Kumaran S, et al. Apoptotic induction and anti-metastatic activity of eugenol encapsulated chitosan nanopolymer on rat glioma C6 cells via alleviating the MMP signaling pathway [Internet]. Vol. 203, Journal of Photochemistry and Photobiology B: Biolo- 
gy. 2020. p. 111773. Available from: http://dx.doi.org/10.1016/j. jphotobiol.2019.111773

14. Wang Y, Zhang Y, Guo Y, Lu J, Veeraraghavan VP, Mohan SK, et al. Synthesis of Zinc oxide nanoparticles from Marsdenia tenacissima inhibits the cell proliferation and induces apoptosis in laryngeal cancer cells (Hep-2) [Internet]. Vol. 201, Journal of Photochemistry and Photobiology B: Biology. 2019. p. 111624. Available from: http://dx.doi.org/10.1016/j.jphotobiol.2019.111624

15. Gan H, Zhang Y, Zhou Q, Zheng L, Xie X, Veeraraghavan VP, et al. Zingerone induced caspase-dependent apoptosis in MCF7 cells and prevents 7,12-dimethylbenz(a)anthracene-induced mammary carcinogenesis in experimental rats [Internet]. Vol. 33, Journal of Biochemical and Molecular Toxicology. 2019. Available from: http://dx.doi.org/10.1002/jbt.22387

16. Rengasamy G, Venkataraman A, Veeraraghavan VP, Jainu M. Cytotoxic and apoptotic potential of Myristica fragrans Houtt. (mace) extract on human oral epidermal carcinoma KB cell lines [Internet]. Vol. 54, Brazilian Journal of Pharmaceutical Sciences. 2018. Available from: http://dx.doi.org/10.1590/s217597902018000318028

17. Ma Y, Karunakaran T, Veeraraghavan VP, Mohan SK, Li S. Sesame Inhibits Cell Proliferation and Induces Apoptosis through Inhibition of STAT-3 Translocation in Thyroid Cancer Cell Lines (FTC-133) [Internet]. Vol. 24, Biotechnology and Bioprocess Engineering. 2019. p. 646-52. Available from: http:// dx.doi.org/10.1007/s12257-019-0151-1

18. Chen F, Tang Y, Sun Y, Veeraraghavan VP, Mohan SK, Cui C. 6-shogaol, An active constiuents of ginger prevents UVB radiation mediated inflammation and oxidative stress through modulating $\mathrm{NrF} 2$ signaling in human epidermal keratinocytes (HaCaT cells). J Photochem Photobiol B. 2019 Aug; 197:111518.

19. G R, Ramya G, V VP, Gayathri R. Cytotoxicity of Strawberry Extract on Oral Cancer Cell Line [Internet]. Vol. 11, Asian Jour- nal of Pharmaceutical and Clinical Research. 2018. p. 353. Available from: http://dx.doi.org/10.22159/ajpcr.2018.v11i9.25955

20. Menon A, V VP, Gayathri R. Preliminary Phytochemical Analysis and Cytotoxicity Potential of Pineapple Extract on Oral Cancer Cell Lines [Internet]. Asian Journal of Pharmaceutical and Clinical Research. 2016. p. 140. Available from: http://dx.doi. org/10.22159/ajpcr.2016.v9s2.13313

21. Jainu M, Priya V, Mohan S. Biochemical evidence for the antitumor potential of Garcinia mangostana Linn. On diethylnitrosamine-induced hepatic carcinoma [Internet]. Vol. 14, Pharmacognosy Magazine. 2018. p. 186. Available from: http://dx.doi. org/10.4103/pm.pm_213_17

22. Mohan SK, Veeraraghavan VP, Jainu M. Effect of pioglitazone, quercetin and hydroxy citric acid on extracellular matrix components in experimentally induced non-alcoholic steatohepatitis. Iran J Basic Med Sci. 2015 Aug;18(8):832-6.

23. Rengasamy G, Jebaraj DM, Veeraraghavan VP. Characterization, Partial Purification of Alkaline Protease from Intestinal Waste of Scomberomorus Guttatus and Production of Laundry Detergent with Alkaline. Indian Journal of Pharmaceutical Education \& Researh [Internet]. 2016; Available from: https://www. ijper.org/sites/default/files/10.5530ijper.50.2.19.pdf

24. Shukri NMM, Vishnupriya V, Gayathri R, Mohan SK. Awareness in childhood obesity [Internet]. Vol. 9, Research Journal of Pharmacy and Technology. 2016. p. 1658. Available from: http:// dx.doi.org/10.5958/0974-360x.2016.00334.6

25. Ponnulakshmi R, Shyamaladevi B, Vijayalakshmi P, Selvaraj J. In silicoandin vivoanalysis to identify the antidiabetic activity of beta sitosterol in adipose tissue of high fat diet and sucrose induced type-2 diabetic experimental rats [Internet]. Vol. 29, Toxicology Mechanisms and Methods. 2019. p. 276-90. Available from: http://dx.doi.org/10.1080/15376516.2018.1545815 